\title{
Interpersonal relationships drive successful team science: an exemplary case-based study
}

\author{
Hannah B. Love (i) ${ }^{1 凶}$, Jennifer E. Cross (i) ${ }^{2}$, Bailey Fosdick (iD ${ }^{2}$, Kevin R. Crooks ${ }^{2}$, Susan VandeWoude ${ }^{2}$ \& \\ Ellen R. Fisher ${ }^{3}$
}

Scientists are increasingly charged with solving complex societal, health, and environmental problems. These systemic problems require teams of expert scientists to tackle research questions through collaboration, coordination, creation of shared terminology, and complex social and intellectual processes. Despite the essential need for such interdisciplinary interactions, little research has examined the impact of scientific team support measures like training, facilitation, team building, and expertise. The literature is clear that solving complex problems requires more than contributory expertise, expertise required to contribute to a field or discipline. It also requires interactional expertise, socialised knowledge that includes socialisation into the practices of an expert group. These forms of expertise are often tacit and therefore difficult to access, and studies about how they are intertwined are nearly nonexistent. Most of the published work in this area utilises archival data analysis, not individual team behaviour and assessment. This study addresses the call of numerous studies to use mixed-methods and social network analysis to investigate scientific team formation and success. This longitudinal case-based study evaluates the following question: How are scientific productivity, advice, and mentoring networks intertwined on a successful interdisciplinary scientific team? This study used applied social network surveys, participant observation, focus groups, interviews, and historical social network data to assess this specific team and assessed processes and practices to train new scientists over a 15-year period. Four major implications arose from our analysis: (1) interactional expertise and contributory expertise are intertwined in the process of scientific discovery; (2) team size and interdisciplinary knowledge effectively and efficiently train early career scientists; (3) integration of teaching/training, research/discovery, and extension/engagement enhances outcomes; and, (4) interdisciplinary scientific progress benefits significantly when interpersonal relationships among scientists from diverse disciplines are formed. This case-based study increases understanding of the development and processes of an exemplary team and provides valuable insights about interactions that enhance scientific expertise to train interdisciplinary scientists.

\footnotetext{
${ }^{1}$ Divergent Science LLC, Fort Collins, CO, USA. ${ }^{2}$ Colorado State University, Fort Collins, CO, USA. ${ }^{3}$ University of New Mexico and Colorado State University, Fort Collins, CO, USA. ${ }^{凶}$ email: Hannah.love15@alumni.colostate.edu
} 


\section{Introduction}

cientists are increasingly charged with solving complex and large-scale societal, health, and environmental challenges (Read et al., 2016; Stokols et al., 2008). These systemic problems require interdisciplinary teams to tackle research questions through collaboration, coordination, creation of shared terminology, and complex social and intellectual processes (Barge and Shockley-Zalabak, 2008; De Montjoye et al., 2014; Fiore, 2008). Thus, to successfully approach complex research questions, scientific teams must synthesise knowledge from different disciplines, create a shared terminology, and engage members of a diverse research community (Matthews et al., 2019; Read et al., 2016). Despite significant time, energy, and money spent on collaboration and interdisciplinary projects, little research has examined the impact of scientific team support measures like training, facilitation, team building, and team performance metrics (Falk-Krzesinski et al., 2011; Klein et al., 2009).

Studies examining the development of scientific teaming skills that result in successful outcomes are sparse (Fiore, 2008; Hall et al., 2018; Wooten et al., 2014). The earliest studies of collaboration in science used bibliometric data to search for predictors of team success such as team diversity, size, geographical proximity, inter-university collaboration, and repeat collaborations (Borner et al., 2010; Cummings and Kiesler, 2008; Wuchty et al., 2007). Building from these studies, current research focuses on team processes. Literature suggests that to successfully frame a scientific problem, a team must also engage emotionally and interact effectively (Boix Mansilla et al., 2016) and that scientific collaboration involve consideration of the process, collaborator, human capital, and other factors that define an scientific collaboration (Bozeman et al., 2013; Hall et al., 2019; Lee and Bozeman, 2005). Similarly, Zhang et al. (2020) used social network analysis to examine how emotional intelligence is transmitted to team outcomes through team processes. Still more research is needed, and Hall et al. (2018) called for team science studies that use longitudinal designs and mixed-methods to examine project teams as they develop in order to move beyond bibliometric measures of success and to explore the complex, interacting features in real-world teams.

Fiore (2008) explained that much of what we know about the science of team science (SciTS), training scientists and team learning in productive team interactions, is anecdotal and not the result of systematic investigation (Fiore, 2008). Over a decade later there is still a paucity of research on how scientific teams develop the type of expertise they need to create new knowledge and further scientific discovery (Bammer et al., 2020). Bammer et al. (2020) has identified and defined two types of expertise: (1) contributory expertise, expertise required to make a contribution to a field or discipline (Collins and Evans, 2007); and (2) interactional expertise, socialised knowledge that includes socialisation into the practices of an expert group (Bammer et al., 2020). These forms of expertise are often tacit, codified by "learning-by-doing," and augmented from project to project; therefore, they are difficult to measure and rarely documented in literature (Bammer et al., 2020).

Wooten et al. (2014) outlined three types of evaluationsdevelopmental, process, and outcome-needed to understand how teams develop and to provide information about their future success (Wooten et al., 2014). A developmental evaluation focuses on the continuous process of team development, and a process evaluation focuses on team interactions, meetings, and engagement (Patton, 2011). Both development and process evaluations have the common goal of understanding the team's future success or failures, also known as the team's outcomes (e.g., grants, publications, and awards) (Patton, 2011). The majority of published work on outcome metrics is evaluated by archival data analysis, not individual team behaviour and assessment (Hall et al., 2018). Albeit informative, these studies are based upon limited outcome metrics such as publications and represent only a selective sampling of teams that have achieved success. To collect these three types of evaluation data, it is recommended to engage mixed-methods research such as a combination of social network analysis (SNA), participant observation, surveys, and interviews, although these approaches have not been widely employed (Bennett, 2011; Borner et al., 2010; Fiore, 2008; Hall et al., 2018; Wooten et al., 2014).

A few key studies have provided insight into successful collaboration strategies. Duhigg (2016) found that successful teams provided psychological safety, had dependable team members, and relied upon clear roles and structures. In addition, successful teams had meaningful goals, and team members felt like they could make an impact through their work on the team (Duhigg, 2016). Similarly, Collins (2001) explained that in business teams, moving from "Good to Great" required more than selecting the right people; the team needed development and training to achieve their goals (Collins, 2001). Woolley et al. (2010) found that it is not collective intelligence that builds the most effective teams, but rather, how teams interact that predicts their success (Woolley et al., 2010). The three traits they identified as most associated with team success included even turn-taking, social sensitivity, and proportion female (when women's representation nears parity with men) (Woolley et al., 2010). Finally, Bammer et al. (2020) recommended creating a knowledge bank to strengthen knowledge about contributary and interactional expertise in scientific literature to solve complex problems. Collectively, these studies argue that the key to collective intelligence is highly reliant on interpersonal relationships to drive team success.

This article reports on a longitudinal case-based study of an exemplary interdisciplinary scientific team that has been successful in typical scientific outputs, including competing for research awards, publishing academic articles, and training and developing scientists. This analysis examines how scientific productivity, advice, and mentoring networks intertwined to promote team success. The study highlights how the team's processes to train scientists (e.g., developing mentoring and advice networks) have propelled their scientific productivity, fulfilled the University's land grant mission (i.e., emphasises research/discovery; education/training; and outreach/engagement) and created contributory and interactional expertise on the team. Team dynamics were evaluated by social network surveys, participant observation, focus groups, interviews, and historical social network data over 15 years to develop theory and evaluate complex relationships contributing to team success (Dozier et al., 2014; Greenwood, 1993).

\section{Methods}

Case study selection. The [BLIND] Science of team science (SciTS) team consisted of scientists trained in four different disciplines and research administrators. The SciTS team monitored twenty-five interdisciplinary teams at [BLIND] for 5 years from initiation of team formation to identify team dynamics that related to team success. This case is thus presented as part of an ongoing study of the 25 teams, supported by efforts through the [BLINDED] to encourage and enhance collaborative, interdisciplinary research and scholarship. Team outcomes were recorded annually and included extramural awards, publications, presentations, students trained, and training outcomes. An exemplary case-based study is appropriate when the case is unusual, the issues are theoretically important, and there are 
practical implications (Yin, 2017). Further, cases can illustrate examples of expertise and provide guidance to future teams (Bammer et al., 2020). An "exemplary team designation" was given to this team by the SciTS evaluators. Metrics used to designate an exemplary team included: team outcomes; highly interdisciplinary research; longevity of the team; fulfilment of all aspects of the land grant mission (research/discovery; education/ training; and outreach/engagement); integration of team members; and use of external reviewers.

Social network survey. The exemplary team included Principle Investigators (PIs), postdoctoral researchers (postdocs), graduate students, undergraduate students, and active collaborators external to the University. The entire team was surveyed annually 2015-2019 about the extent and type of collaboration with other team members. In 2015, the team was asked about prior collaborations, and in subsequent years they were asked about additional interactions since joining the team. Possible collaborative activities included research publications, scientific presentations, grant proposals, and serving on student committees. Team members were also asked the types of relationships they had with each team member, including learning, leadership, mentoring, advice, friendship, and having fun (Supplementary 2). Data were collected using a voluntary online survey tool (Organisational Network Analysis Surveys). All subjects were identified by name on the social network survey but are not identified in any network diagrams or analyses. SNA software programmes R Studio (R Studio Team, 2020) and UCINET (Borgatti et al., 2014) were used to analyse data and Visone (Brandes and Wagner, 2011) was used to create visualisations. The response rate for the survey was $94 \%$ in $2015,83 \%$ in $2016,95 \%$ in 2017 , and $81 \%$ in 2018 . All data collection methods were performed with the informed consent of the participants and followed Institutional Review Board protocol \#19-8622H.

Data from the social network survey were combined to create three different network measures: scientific productivity, mentoring, and advice. The scientific productivity network was a combination of four survey measures: research/consulting, grants, publications, and serving on student committees. Scientific productivity represents a form of cognitive or contributory expertise: expertise required to contribute to a field or discipline (Bammer et al., 2020; Boix Mansilla et al., 2016). The mentoring and advice networks were created from social network survey questions: "who is your mentor?" and "who do you go to for advice?", respectively. Mentor and advice are tacit forms of interactional expertise: socialised knowledge that includes socialisation into the practices of an expert group (Collins and Evans, 2007). Other studies have also found a connection between social characteristics of interdisciplinary work and other factors like productivity, career paths, and a group's ability to exchange information, interact, and explore together (Boix Mansilla et al., 2016).

Social network data were summarised using average degree, sometimes split into indegree and outdegree. Outdegree is a measure of how many team members a given individual reported getting advice, or mentorship, from. Similarly, the indegree of an individual is a measure of how many other team members reported receiving advice, or mentorship, from that person. Average degree is the average number of immediate connections (i.e., indegree plus outdegree) for a person in a network (Giuffre, 2013; R. Hanneman and Riddle, 2005a, 2005b). To further explore the mentoring and advice networks, we calculated the average degree/outdegree/indegree of postdocs, graduate students, and faculty separately to directly compare demographic groups.
The advice, mentoring, and scientific productivity networks were directly compared using the Pearson correlation between the corresponding network adjacency matrices. We predicted a positive correlation between the advice, mentoring, and scientific productivity matrices. Statistical significance $(p<0.05)$ of correlations was assessed with the network permutation-based method Quadratic Assignment Procedure (QAP) (R. A. Hanneman and Riddle, 2005a, 2005b).

Historical social network data. A historical network survey was created to determine how the connections in the network formed, developed, and changed from project-to-project. The historical social network was constructed from three forms of data: interviews with the PIs, a historical narrative written by the PIs describing the team formation process, and team rosters that listed the 81 team members since the inception of the team.

Retrospective team survey. A retrospective team survey was administered at the end of the study to determine what skills team members developed and codified through participating on the team, how membership on the team supported members personally and professionally, and their favourite aspects of the team. The survey was sent to 22 members from the 2018 team roster using Qualtrics (Qualtrics Labs, 2005) with an 86\% response rate.

Interviews. Two semi-structured, one-hour interviews were conducted with two PIs in 2018 to learn about the history of the team. The interviews were digitally recorded and transcribed.

Participant observations. Participant observation was conducted from 2015-2019 at four annual three-day, off-campus retreats and 1-2 additional meetings each year. Students, PIs, external collaborators, and families were all invited to attend the retreats and meetings. Field notes about team interactions were recorded immediately after each interaction. The analytic field notes captured how team members interacted across disciplines, tackled scientific problems, and engaged with others at different career stages. Analysis occurred as field notes were written, during observations, and again during data analysis.

\section{Results}

An exemplary team. The SciTS Team identified one team from the larger study and designated it as exemplary based on six (tacit and non-tacit) elements. First, the team had outstanding team outcomes. From 2004-2018, notable accomplishments include 33 extramural awards totalling over $\$ 5.6$ million, including two large federal awards totalling over $\$ 4.5$ million; 58 peer-reviewed publications with 39 different universities, 13 state agencies, and 11 other organisations; 141 presentations, 21 graduate students and 15 postdocs trained; and receipt of an [BLIND]institutionwide Interdisciplinary Scholarship Team Award. Participants received many individual honours, including one of the PIs being named to the National Academy of Sciences.

Second, this interdisciplinary team combined scientific expertise from many different backgrounds, including ecologists, wildlife biologists, evolutionary biologists, geneticists, veterinarians, and numerous collaborators. Principal Investigators were housed in five main universities: Colorado State University, University of Wyoming, University of Minnesota, University of California-Davis, and University of Tasmania. They also engaged collaborators from national and international universities, federal, state, and local governmental agencies, veterinary centres, and animal shelters. Collectively, team members represented 39 different universities, 11 federal agencies, 13 state agencies, and 11 other organisations listed on their peer-reviewed publications. 


\section{Timeline of Major Events in Team Development and Formation}

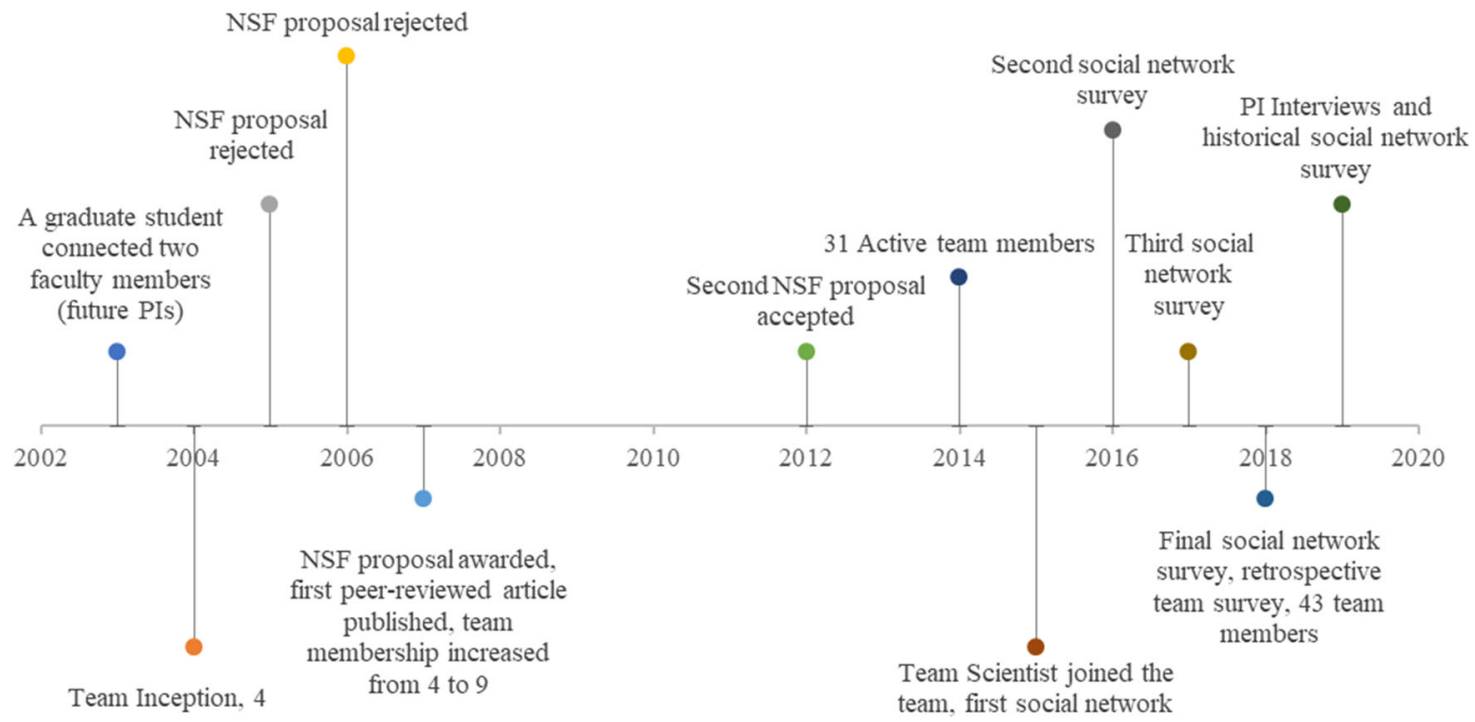

Fig. 1 Timeline of major events in team development and formation. Significant events occurring over 15 years during the development and formation of an exemplary team.

The team has published globally with co-authors from every continent but Antarctica.

The third element identified was the team's 15-year history and how they evolved project-to-project (Supplementary Video S1). In 2003, a graduate student proposed a collaborative research project between two faculty members who became two of the founding team PIs (Fig. 1). The team was formed in 2004 with four members-two faculty PIs, a postdoc, and a Ph.D. student (Fig. 1). Initial grant proposals submitted in 2005 and 2006 were not funded; however, in 2007, the team received a large federal research award from the US National Science Foundation (NSF). The team roster increased from four to nine, and a second large expansion occurred after receipt of another NSF award in 2012. By 2014, membership increased to 31 people, and at the end of analysis in 2018, the roster comprised 43 members. Over the course of observation, 81 different individuals, including students, faculty, and collaborators, had participated in research activities supported by the team.

The fourth reason this team was deemed exemplary was because it intertwined the components in the Land Grand mission, including research/discovery, teaching/training, and extension/engagement (Fig. 2). The team included undergraduates conducting research and presenting at conferences, graduate students working in multiple labs, and postdocs mentoring all the researchers in the lab. An external advisor said at the end of a retreat, "It's really cool that students are part of the conversations that are both good/bad/ugly etc. It is not just good. It is not just one-on-one conversations. They hear it all." A Ph.D. student wrote in the Retrospective Survey about the skills he developed: "I have developed the ability to talk about my research to people outside my field. I have also worked on broadening my understanding of disease ecology as a whole. I have been given the opportunity [to] begin placing my work in the larger framework of ecosystem health." Faculty also wrote about what they learned, "[I] Learned from leadership of team (especially [blinded], and other PIs) how to develop and conduct research team work well - am using what I am learning to develop new research teams.... how to develop and nurture and respect interpersonal relationships and diversity of opinions. This has been an amazing experience, to be part of a well-functioning team, and to examine why and how that is maintained"

Fifth, the team was effective at onboarding and integrating new members. To do so, they used two key strategies (Fig. 3). First, 15 of the students held co-advised graduate research positions. This shared model of mentorship provided students with opportunities to work in multiple labs, collaborate with additional team members, and gain a broader academic experience. A Ph.D. student wrote in the Retrospective Survey about the skills she learned from being a member of the team: "Leadership skills, communicating science to those in other fields, scientific writing skills, technical laboratory skills, interpersonal communication skills, data sharing experience, and many others." The shared model supported the team's interdisciplinary mission by providing opportunities to train future scientists to communicate, network, and conduct research across disciplines. Second, as team members developed through participation on the team, they assumed more mature scientific roles. Fourteen members of the team changed positions within the team. Many of these transitions were from undergraduate student to $\mathrm{Ph}$. D. student or Ph.D. student to postdoctoral researcher. In 2012, one postdoc became a PI on the grant.

Finally, the 2018 team retreat included external reviewers. At the end of 2018 team retreat, they were asked if they had any feedback for the team. An external reviewer said: "You can check all of the boxes of a good team."; "This is a dream team."; "I am really impressed.". Another external reviewer said:

The ambitiousness to execute the scope of the project, to have this many PIs, to be able to communicate; the opportunities for new insights; and the opportunities it presents for trainees are rare. There are a lot of people exposed in this. This is a unique experience for someone in training. And it extends to elementary school. I don't think there are many projects that have this type of scope. I was impressed with just the idea that scientists are taking this across such a great scope and taking on such great questions.

Scientific productivity network. Prior to 2016, the average degree of the scientific productivity network was 8.8 (Fig. 4). In 


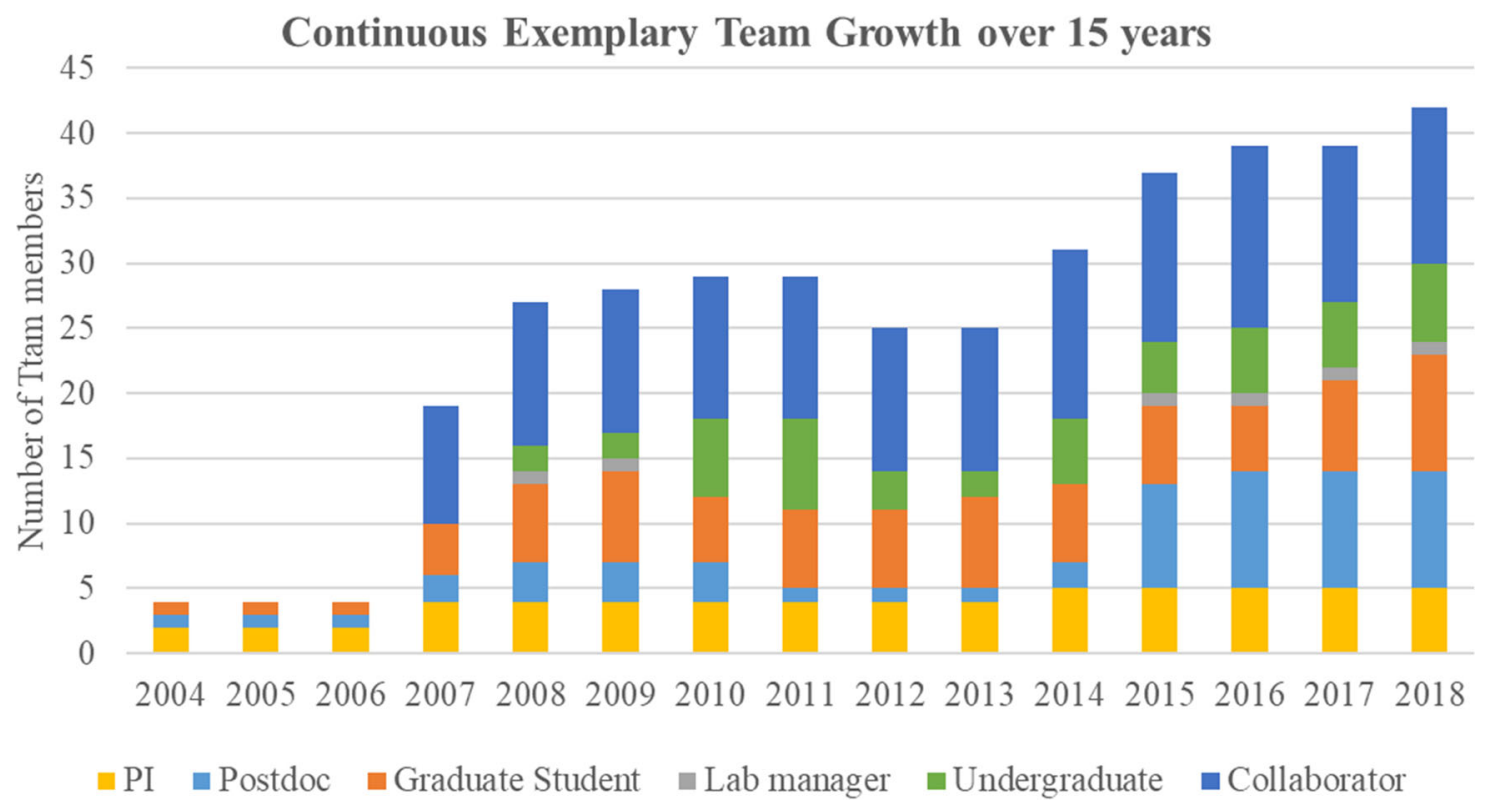

Fig. 2 Continuous exemplary team growth over $\mathbf{1 5}$ years. The team grew from 4 members in 2004 to 42 members in 2018. Much of the growth occurred by the addition of students and external collaborators.

2016, four faculty nodes were in the core of the network, and the periphery nodes included graduate students, postdocs, and external collaborators (Fig. 5). The average degree dropped slightly to 6.2 when the team integrated new members and reformed around new roles and responsibilities on a new grant (Fig. 4). In 2017, the average degree peaked at 9.7 (Fig. 4) and faculty were still core, but graduate students and postdocs were more central than before (Fig. 5). During this time, productivity was at its highest as team members were working together to meet the objectives of a 5-year interdisciplinary NSF award. The network evolved further in 2018; two of the postdoc nodes overlapped with the faculty nodes in the core of the network (Fig. 5).

Mentoring is integral in the collaborative network. Team members reported between an average of 2.4-3.1 mentors (average outdegree) each year on the team (Fig. 6). More specifically, graduate students reported 6.0-7.7 mentors, whereas postdocs reported 2.4-3.5 mentors (Table 1). Faculty team members reported having an average of 2.2 to 4.3 mentors on the team (Table 1), with the highest average outdegree in 2018.

The highest indegree for an individual was the lead PI, with an indegree ranging from 13 to 14 each year (i.e., each year, 13-14 team members reported this individual provided mentorship). In response to an interview question about this PIs favourite part of the team, this individual said, "... and of course, I really like the mentorship of the students...They are initially naive, and some people are initially underconfident, but eventually they become fluent in their subject area." Many students wrote about the mentoring they received from the team. An undergraduate student wrote:

I have improved my communication skills after needing to collaborate with several mentors across different time zones. I've also improved willingness to ask questions when I don't understand a concept. I've also learned what concepts I find basic in my field that others outside my discipline are less familiar with.

Faculty also wrote about the mentoring they received, such as, "I continually learn from members in the team and mentorship by the more experienced members has supported my own career progression."
Advice is integral in the collaborative network. In the 2015-2017 advice network diagrams, the faculty were tightly clustered (Fig. 7). In 2018, the cluster separated as postdocs and graduate students joined the centre of the network. On average, team members reported 5.1 to 6.4 people they could go to for advice (Fig. 4).

In a survey, faculty responded to the question, "How has the team supported you personally and professionally?" One faculty member wrote: "Just today I asked three members of the team for professional advice! And got a thoughtful and prompt response from all." Another team member wrote: "Being a member of the...team has allowed me to develop skills in statistical analysis, scientific writing, and critical thinking. This team has opened my eyes to what is possible to achieve with science and has provided me with opportunities to network and expand my horizons both within the field of study and outside of it." These quotes further suggest that the mentoring and advice from a large interdisciplinary team were important to train future scientists.

Interpersonal relationships as driver for scientific productivity. The mentoring and advice networks supported and built on the scientific productivity network and vice versa. The correlation between the collaboration, mentoring, and advice networks would not be possible if the networks were not intertwined. In the retrospective survey, a faculty member described how tacit interpersonal relationships were correlated with their scientific productivity:

Being a part of this grant has helped me both personally and professionally by teaching me new skills (disease ecology, team dynamics), developing friendships/mentors from the team, and strengthening my CV and dossier for promotion to early full professorship.

A Ph.D. student also described how the relationships on the large team propelled their research.

Membership on this team has provided me with a lot of mentorship that I would not otherwise receive were I not working on a large multi-disciplinary for my doctoral research. It has also allowed me to network more effectively. 


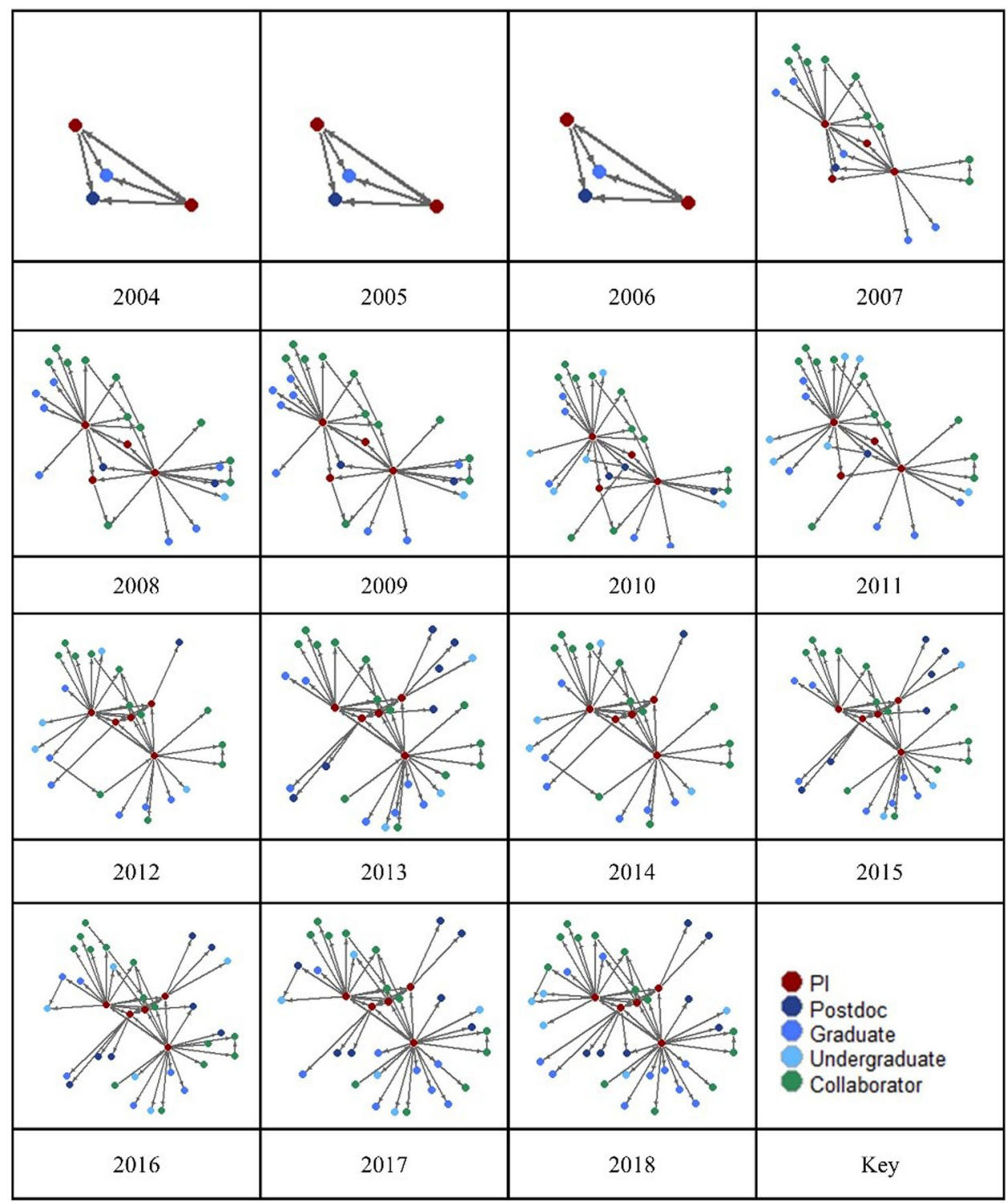

Fig. 3 Team longevity contributes to growth and development of scientists. Social network diagrams of team growth and development from 2004-2018. This network reports onboarding and integration of all members, including their primary position when they joined the team. The nodes are sized by average degree (see text). Colours denote different roles on the team.

Between 2015 and 2018, the mentor and advice networks were significantly correlated with the scientific productivity network, demonstrating that personal relationships are associated with scientific collaboration (Table 2).

\section{Discussion}

To date, the literature examining successful interdisciplinary scientific team skills that result in successful outcomes is sparse (Fiore, 2008; Hall et al., 2018; Wooten et al., 2014). The majority of published work in this area is evaluated by archival data analysis, not individual team behaviour and assessment (Hall et al., 2018). This study answers the call of numerous researchers to use mixed-methods and SNA to investigate scientific teams (Bennett, 2011; Borner et al., 2010; Hall et al., 2018; Woolley et al., 2010; Wooten et al., 2015). Our case-based study also increases understanding of the development and processes of an exemplary team by providing valuable insights about how the interactions that enhance scientific productivity are synergistic with the interactions that train future scientists. There are four major implications of our findings: (1) interactional and contributory expertise are intertwined; (2) team size, tacit knowledge gained from previous project, and interdisciplinary knowledge were used to effectively and efficiently train scientists; (3) the team increased scientific productivity through interpersonal relationships; and (4) the team fulfilled the land grant mission of the University by integrating teaching/training, research/discovery, and extension/ engagement into the team's activities.

Interactive and contributory expertise are intertwined. Previous literature on scientific teams has found that great teams are not built on scientific expertise alone, but on the processes and interactions that build psychological safety, create a shared language, engage members emotionally, and promote effective interactions (Boix Mansilla et al., 2016; Hall et al., 2019; Senge, 1991; Woolley et al., 2010; Zhang et al., 2020). The team highlighted in this report created a shared language and vision through the mentoring and advice networks that helped fuel the team's scientific productivity (Hall et al., 2012). To solve complex problems requires more than contributory expertise, it also requires interactional expertise (Bammer et al., 2020). These 


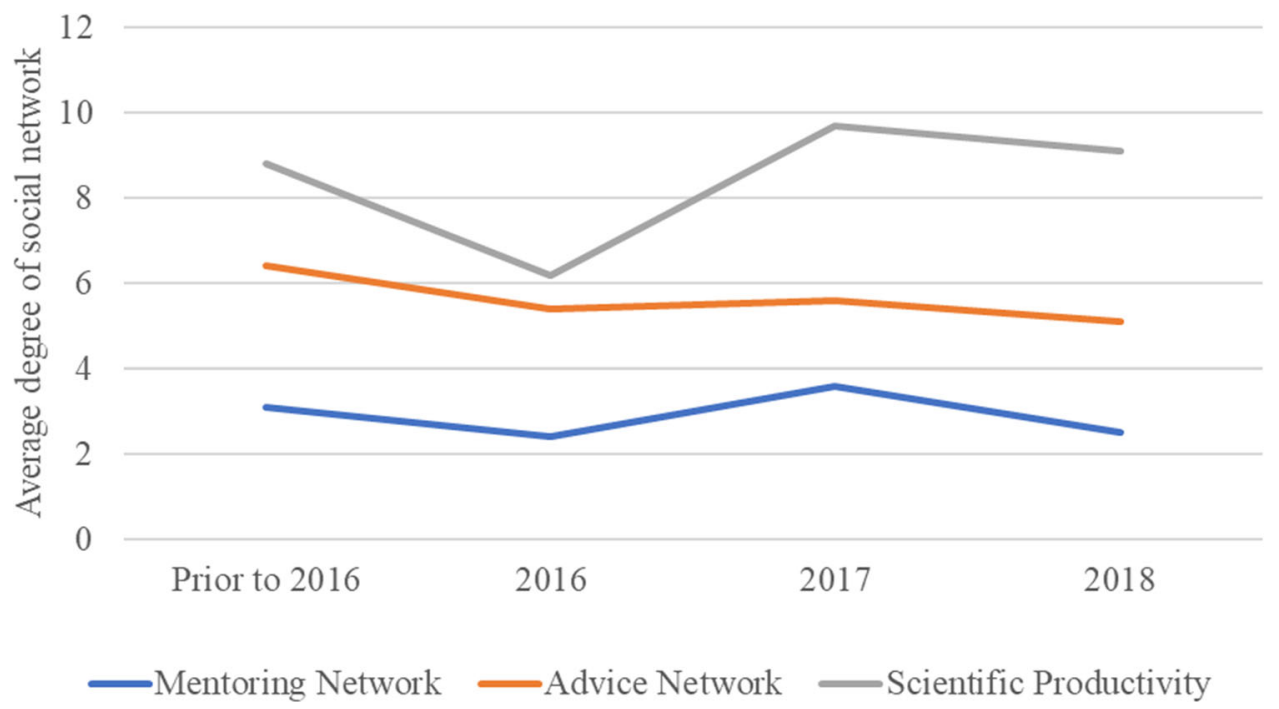

Fig. 4 Robust patterns of collaboration over time. Average degree of social networks diagrams (mentoring, advice, scientific productivity) indicated strong social ties among team members.

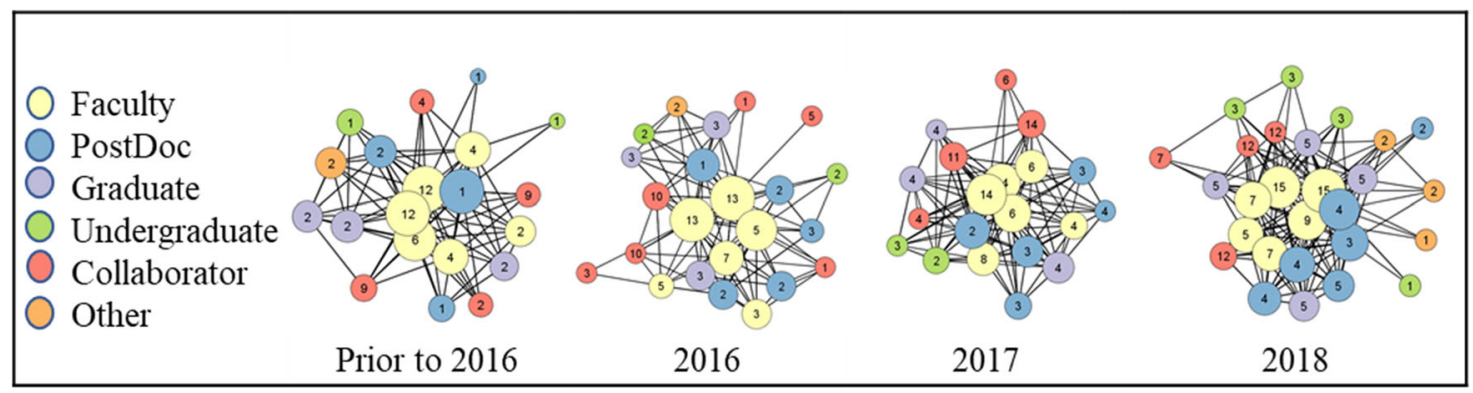

Fig. 5 Over time, junior scientists migrated to be core members of the scientific productivity network. Social network measures of productivity (research/consulting, grants, publications, and serving on student committees) were recorded over time. Each node represents a person on the team, and nodes are sized by average degree (see text). Colours denote different roles on the team. The node label indicates the number of years a person has been part of the team.

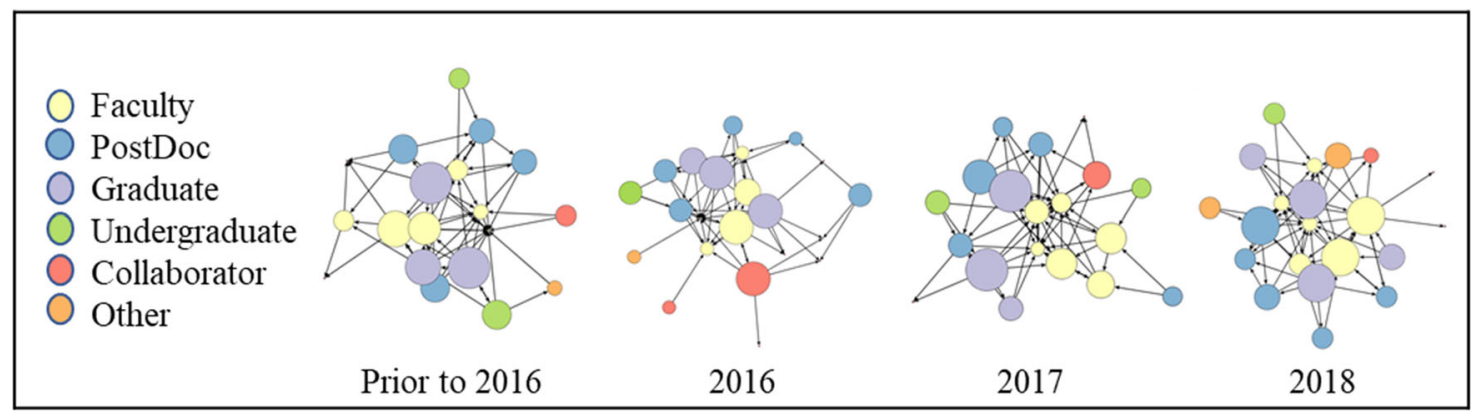

Fig. 6 Mentoring trains future scientists. This diagram was created by using participant answers to the social network question, "who is your mentor?" Each circle or node represents a person on the team. The nodes are sized by outdegree to show who reported receiving mentorship. Node size indicates how many mentors an individual reported, and arrows indicate nodes that served as mentors. Colours denote different roles on the team.

forms of expertise are often tacit and internalised through the process of becoming an expert in a field of study (Collins and Evans, 2007). Learning-by-doing is augmented from project-toproject, with expertise codified over time (Bammer et al., 2020). Further, cognitive, emotional, and interactions are key components of successful collaborations (Boix Mansilla et al., 2016; Bozeman et al., 2013; Zhang et al., 2020). Using social network analysis, our case-based analysis found that the mentoring and advice ties were intertwined with the scientific productivity network.
Training scientists to be experts. The Retrospective Survey asked what personal and professional skills respondents learned from being a member of a team. We hypothesised that many respondents would report tangible skills. Surprisingly, $82 \%$ of the openended responses were about tacit skills. Students frequently had co-advised graduate research positions, worked in multiple labs, and communicated regularly with practitioners. Moreover, the team translated research to different disciplines within the team, mentored others, and managed interpersonal conflicts. These interactions built expertise because training was not limited to 
Table 1 Mentoring network metrics.

\begin{tabular}{|c|c|c|c|c|c|c|c|}
\hline Year & $\mathbf{N}$ & Average degree & \multicolumn{3}{|l|}{ Average outdegree } & \multicolumn{2}{|c|}{ Average indegree } \\
\hline 2015 & 18 & 3.1 & 7.7 & 3.5 & 2.7 & 2.0 & 7.2 \\
\hline 2017 & 20 & 3.6 & 6.0 & 3.3 & 3.3 & 2.4 & 7.2 \\
\hline 2018 & 27 & 2.5 & 6.3 & 3.0 & 4.3 & 2.8 & 8.2 \\
\hline
\end{tabular}

Average outdegree indicates, on average, how many mentors graduate students, postdocs, and faculty have on the team. Average indegree indicates, on average, how many postdocs and faculty serve as mentors for others on the team. Average degree is the average of both the outdegree and indegree.

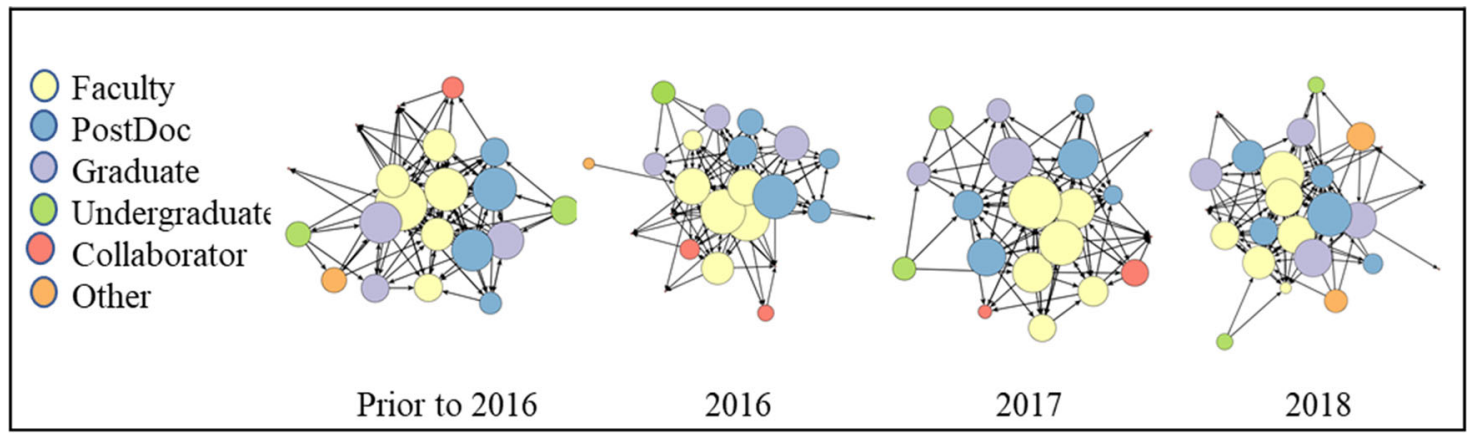

Fig. 7 Advice network is integral to building expertise. This diagram was created by using participant answers to the social network question, "who do you go to for advice?" Each circle or node represents a person on the team. The nodes are sized by outdegree to show who reported receiving mentorship. Node size indicates how many mentors an individual reported, and arrows indicate nodes that served as mentors. Colours denote different roles on the team.

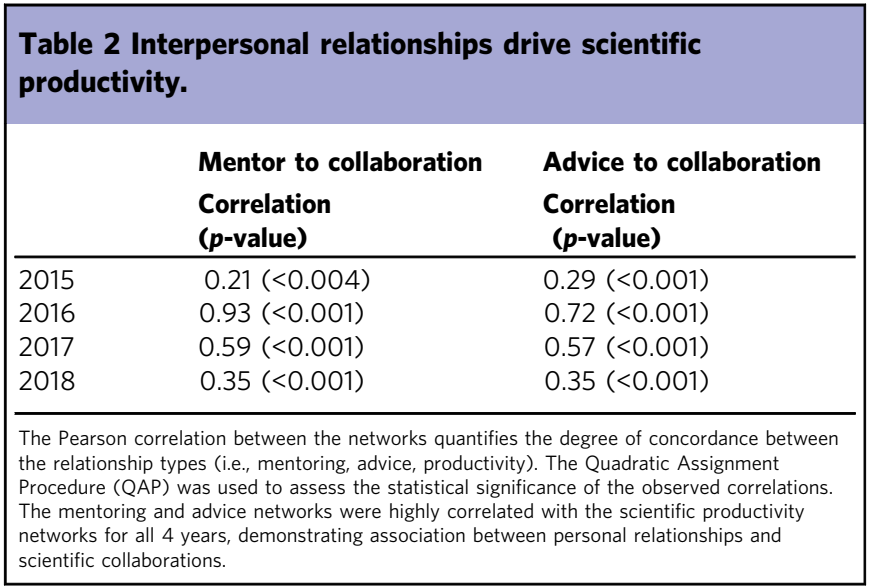

research in a single lab or only in an academic setting. Simple, discrete, and codified knowledge is relatively easy to transfer; however, teams need stronger relationships to gain complex and tacit knowledge, (Attewell, 1992; Simonin, 1999). On this team, interactions and the ability to practice communication were especially influential for students, junior scientists, and new members. These individuals provided survey responses reporting they learned a wide variety of skills ranging from leadership, scientific and interpersonal communication, networking across disciplines, scientific writing, laboratory techniques, and data sharing standards. Further, respondents noted they had gained experience in developing, nurturing, and respecting interpersonal relationships and diversity of opinions. This was reinforced with participant observation data. In other interdisciplinary groups studied in conjunction with this exemplary team, students were not typically exposed to the inner workings of the team such as leadership meetings. On this team, students were exposed to all conversations, which became an important component of the mentoring and advice structure, serving to train future scientists in all aspects of team integration and leadership development. Belonging to this large interdisciplinary team was effectively training, building, and structuring the team.

Interpersonal relationships increase scientific productivity. Longevity of relationships is an important factor in creating social cohesion, reducing uncertainty, and increasing reliability and reciprocity (Baum et al., 2007; Gulati and Gargiulo, 1999; Phelps et al., 2012). Previous literature has, however, rarely documented the importance of time in building the structure of the network (Phelps et al., 2012) and few longitudinal studies of scientific teams exist. Further, it has long been hypothesised that greater interaction among people increases the quality and innovativeness of ideas generated, which may in turn increase productivity (Cimenler et al., 2016). Our case-based study found that the mentoring and advice ties existed in a symbiotic relationship with the scientific productivity network where the practices of the team were simultaneously training scientists. This aligns with social network literature that interactions can structure the social network and the network structure influences interactions (Henry, 2009; Phelps et al., 2012). Second, intentional mentoring programmes have demonstrated a positive relationship between interdisciplinary mentoring and increased research productivity outcomes such as grant funding and publications (Spence et al., 2018). Finally, this finding also aligns with literature on the generation of new knowledge (Phelps et al., 2012). Knowledge creation has traditionally been framed in terms of individual creativity, but recent studies have placed more emphasis on how the contribution of social dynamics are influential in explaining this process (Boix Mansilla et al., 2016; Csikszentmihalyi, 1998; Phelps et al., 2012; Sawyer, 2003; Zhang et al., 2009). Thus, while 
we might think that science drives the team, in this case-based study, the team's interpersonal relationships were the driver of the team's scientific productivity.

Fulfilling the land grant mission. As noted above, this exemplary team fulfilled all three goals of the land grant mission. First, the team was training scientists at all levels, from undergraduate students, to graduate students, postdocs, new faculty, and external collaborators, including community partners. In many instances, the training and mentoring was structured in a vertically integrated manner. For example, postdocs were training graduate and undergraduate students, typical of many teams. In addition to the "top-down" scenarios, however, the team also encouraged training that went from the bottom up as well. Effectively, this is a hallmark of successful teams in other sectors such as emergency responders and elite military teams - whomever has the knowledge to drive the issue at hand is the effective "leader" in that mission (Kotler and Wheal, 2008). Second, the team excelled in research and discovery, partnering with a diversity of external collaborators to do so. This created a network structure wherein the team clearly utilised the collaborators for mentoring and advice. Organisations with a core-periphery network structure like this team have been reported to be more creative because ties on the periphery, such as external collaborators, can span boundaries and access diverse information (Perry-Smith, 2006; Phelps et al., 2012). Finally, because the team's collaborators included community partners and practitioners, they were also influencing policy and practice. This resulted in an overall greater impact for the team's science and allowed them to tailor their research to best meet the needs of society (Barge and Shockley-Zalabak, 2008).

Future research. This study provides a unique contribution to team science literature because it longitudinally studied the development and processes of a successful interdisciplinary team (Wooten et al., 2014). Future research on the elements of effective interdisciplinary teaming is required in five key areas. First, identification of best practices that inhibit or support teams is necessary (Fiore, 2008; Hall et al., 2018; Wooten et al., 2014). Second, previous research has found that small teams are best at disrupting science with new ideas and opportunities ( $\mathrm{Wu}$ et al., 2019); however, practices large teams use to create new knowledge have been poorly documented. Third, successful training concepts for graduate students and postdoctoral researchers need additional consideration (Knowlton et al., 2014; Ryan et al., 2012; Sarraj et al., 2017). Fourth, we hypothesise that graduate students act as bridges in teams to connect scientific disciplines and prevent clustering the network. Future research should investigate the role of graduate students in creating knowledge through interdisciplinary teams. Finally, additional research is needed to better recognise and reward scientists who undertake integration and implementation (Bammer et al., 2020).

\section{Data availability}

The datasets generated during and analysed during the current study are available in the Mountain Scholar repository, https:// doi.org/10.25675/10217/214187

Received: 2 January 2021; Accepted: 14 April 2021;

Published online: 06 May 2021

\section{References}

Attewell P (1992) Technology diffusion and organizational learning: the case of business computing. Organ Sci 3(1):1-19. https://doi.org/10.1287/orsc.3.1.1
Bammer G, O’Rourke M, O’Connell D, Neuhauser L, Midgley G, Klein JT, ... Richardson GP (2020). Expertise in research integration and implementation for tackling complex problems: when is it needed, where can it be found and how can it be strengthened? Palgrave Commun, 6(1). https://doi.org/10.1057/ s41599-019-0380-0

Barge JK, Shockley-Zalabak P (2008) Engaged scholarship and the creation of useful organizational knowledge. J Appl Commun Res 36(3):251-265. https:// doi.org/10.1080/00909880802172277

Baum JAC, McEvily B, Rowley T (2007) Better with age? Tie longevity and the performance implications of bridging and closure. SSRN (vol. 23). INFORMS. https://doi.org/10.2139/ssrn.1032282

Bennett ML (2011) Collaboration and team science: a field guide-team science toolkit. Retrieved February 19, 2019, from https://www.teamsciencetoolkit. cancer.gov/Public/TSResourceTool.aspx?tid $=1 \&$ rid $=267$

Boix Mansilla V, Lamont M, Sato K (2016) Shared cognitive-emotional-interactional platforms: markers and conditions for successful interdisciplinary collaborations. Sci Technol Human Value 41 (4):571-612. https://doi.org/10.1177/0162243915614103

Borgatti SP, Everett MG, Freeman LC (2014) UCINET. Encyclopedia of social network analysis and mining. Springer New York, New York, NY, 10.1007/ 978-1-4614-6170-8_316

Borner K, Contractor N, Falk-Krzesinski HJ, Fiore SM, Hall KL, Keyton J, Uzzi B (2010). A multi-level systems perspective for the science. Sci Transl Med 2: 49

Bozeman B, Fay D, Slade CP (2013, February 28). Research collaboration in universities and academic entrepreneurship: the-state-of-the-art. J Technol Transf https://doi.org/10.1007/s10961-012-9281-8

Brandes U, Wagner D (2011) Analysis and visualization of social networks. Springer, Berlin, Heidelberg, pp. 321-340. 10.1007/978-3-642-18638-7_15

Cimenler O, Reeves KA, Skvoretz J, Oztekin A (2016) A causal analytic model to evaluate the impact of researchers' individual innovativeness on their collaborative outputs. J Model Manag 11(2):585-611

Collins H, Evans R (2007) Rethinking expertise. University of Chicago Press, Chicago

Collins JC (2001) Good to great. HarperBusiness, New York, NY

Csikszentmihalyi M (1998) Implications of a systems perspective for the study of creativity. In: Sternberg R (ed) Handbook of creativity (pp. 313-336. Cambridge University Press, Cambridge, England. https://doi.org/10.1017/ CBO9780511807916.018

Cummings JN, Kiesler S (2008) Who collaborates successfully? prior experience reduces collaboration barriers in distributed interdisciplinary research. Cscw: $2008 \mathrm{Acm}$ conference on computer supported cooperative work, Conference Proceedings, pp. 437-446. https://doi.org/10.1145/1460563.1460633

De Montjoye YA, Stopczynski A, Shmueli E, Pentland A, Lehmann S (2014) The strength of the strongest ties in collaborative problem solving. Sci Rep 4. https://doi.org/10.1038/srep05277

Dozier AM, Martina CA, O’Dell NL, Fogg TT, Lurie SJ, Rubinstein EP, Pearson TA (2014) Identifying emerging research collaborations and networks: method development. Eval Health Prof 37(1):19-32. https://doi.org/10.1177/ 0163278713501693

Duhigg Ch (2016) What google learned from its quest to build the perfect teamThe New York Times. Retrieved December 2, 2017, from https://www. nytimes.com/2016/02/28/magazine/what-google-learned-from-its-quest-tobuild-the-perfect-team.html

Falk-Krzesinski HJ, Contractor N, Fiore SM, Hall KL, Kane C, Keyton J, Trochim W (2011) Mapping a research agenda for the science of team science. Res Eval 20(2):145-158. https://doi.org/10.3152/095820211X12941371876580

Fiore SM (2008) Interdisciplinarity as teamwork. Small Group Res 39(3):251-277. https://doi.org/10.1177/1046496408317797

Giuffre K (2013) Communities and networks: using social network analysis to rethink urban and community studies, 1st edn. Polity Press, Cambridge MA, $10.1177 / 0042098015621842$

Greenwood RE (1993) The case study approach. Bus Commun Q 56(4):46-48. https://doi.org/10.1177/108056999305600409

Gulati R, Gargiulo M (1999) Where do interorganizational networks come from? Am J Sociol 104(5):1439-1493. https://doi.org/10.1086/210179

Hall KL, Vogel AL, Croyle RT (2019) Strategies for team science success: handbook of evidence-based principles for cross-disciplinary science and practical lessons learned from health researchers. Springer Nature, Switzerland

Hall KL, Vogel AL, Huang GC, Serrano KJ, Rice EL, Tsakraklides SP, Fiore SM (2018) The science of team science: a review of the empirical evidence and research gaps on collaboration in science. Am Psychol 73(4):532-548. https:// doi.org/10.1037/amp0000319

Hall KL, Vogel AL, Stipelman BA, Stokols D, Morgan G, Gehlert S (2012) A fourphase model of transdisciplinary team-based research: goals, team processes, and strategies. Transl Behav Med 2(4):415-430. https://doi.org/10.1007/ s13142-012-0167-y

Hanneman RA, Riddle M (2005a) Introduction to social network methods: table of contents. Riverside, CA. Retrieved from http://faculty.ucr.edu/ hanneman/nettext/ 
Hanneman R, Riddle M (2005b) Introduction to social network methods. Retrieved from http://www.researchgate.net/profile/Robert_Hanneman/publication/ 235737492_Introduction_to_social_network_methods/links/0deec52261e15 77e6c000000.pdf

Henry AD (2009). Society for human ecology the challenge of learning for sustainability: a prolegomenon to. source: human ecology review (Vol. 16). Retrieved from https://www-jstor-org.ezproxy2.library.colostate.edu/stable/ pdf/24707537.pdf?refreqid=excelsior\%3Ae9ffb98fef69c055ab05ead486b9ca7e

Klein C, DiazGranados D, Salas E, Le H, Burke CS, Lyons R, Goodwin GF (2009) Does team building work? Small Group Res 40(2):181-222. https://doi.org/ $10.1177 / 1046496408328821$

Knowlton JL, Halvorsen KE, Handler RM, O’Rourke M (2014) Teaching interdisciplinary sustainability science teamwork skills to graduate students using in-person and web-based interactions. Sustainability (Switzerland) 6 (12):9428-9440. https://doi.org/10.3390/su6129428

Kotler S, Wheal J (2008) Stealing fire: how silicon valley, the navy seals, and maverick scientists are revolutionising the way we live and work. Visual Comput (vol. 24). Retrieved from https://qyybjydyd01.storage.googleapis. com/MDA2MjQyOTY1NQ==01.pdf

Lee S, Bozeman B (2005) The impact of research collaboration on scientific productivity. Soc Stud Sci 35(5):673-702. https://doi.org/10.1177/0306312705052359

Matthews NE, Cizauskas CA, Layton DS, Stamford L, Shapira P (2019) Collaborating constructively for sustainable biotechnology. Sci Rep 9(1):19033. https://doi.org/10.1038/s41598-019-54331-7

Patton MQ (2011) Developmental evaluation: applying complexity concepts to enhance innovation and use. Guilford Press

Perry-Smith JE (2006) Social yet creative: the role of social relationships in facilitating individual creativity. Acad Manag J 49(1):85-101. https://doi.org/ 10.5465/AMJ.2006.20785503

Phelps C, Heidl R, Wadhwa A, Paris H (2012) Agenda knowledge, networks, and knowledge networks: a review and research. J Manag 38(4):1115-1166. https://doi.org/10.1177/0149206311432640

Qualtrics Labs I (2005). Qualtrics Labs, Inc. Provo, Utah, USA

R Studio Team (2020) RStudio: Integrated Development for R. RStudio, PBC, Boston, MA, http://www.rstudio.com/

Read EK, O'Rourke M, Hong GS, Hanson PC, Winslow LA, Crowley S, Weathers KC (2016) Building the team for team science. Ecosphere 7(3):e01291. https://doi.org/10.1002/ecs2.1291

Ryan MM, Yeung RS, Bass M, Kapil M, Slater S, Creedon K (2012) Developing research capacity among graduate students in an interdisciplinary environment. High Educ Res Dev 31(4):557-569. https://doi.org/10.1080/07294360.2011.653956

Sarraj H, Hellmich M, Chao C, Aronson J, Cestone C, Wooten K, Allan, B (2017) Training future team scientists: reflections from translational course. In: Team science training for graduate students and postdocs. Clearwater, FL. Retrieved from www.scienceofteamscience.org

Sawyer RK (2003) Emergence in creativity and development. In: Sawyer RK, JohnSteiner V, Moran S., Sternberg RJ, Nakamura J et al. (eds.) Creativity and development. Oxford University Press, Oxford, England, pp. 12-60

Senge PM (1991) The fifth discipline, the art and practice of the learning organization. Perform Instruct 30(5):37-37. https://doi.org/10.1002/pfi.4170300510

Simonin BL (1999) Ambiguity and the process of knowledge transfer in strategic alliances. Strateg Manag J 20(7):595-623. 10.1002/(SICI)1097-0266(199907) 20:7<595::AID-SMJ47>3.0.CO;2-5

Spence JP, Buddenbaum JL, Bice PJ, Welch JL, Carroll AE (2018) Independent investigator incubator (I3): a comprehensive mentorship program to jumpstart productive research careers for junior faculty. BMC Med Educ 18 (1):1-11. https://doi.org/10.1186/s12909-018-1290-3

Stokols D, Misra S, Moser RP, Hall KL, Taylor BK (2008). The ecology of team science. Understanding contextual influences on transdisciplinary collaboration. Am J Prevent Med https://doi.org/10.1016/j.amepre.2008.05.003

Woolley AW, Chabris CF, Pentland A, Hashmi N, Malone TW (2010) Evidence for a collective intelligence factor in the performance of human groups. Science 330(6004):686-688. https://doi.org/10.1126/science.1193147

Wooten KC, Calhoun WJ, Bhavnani S, Rose RM, Ameredes B, Brasier AR (2015) Evolution of multidisciplinary translational teams (MTTs): insights for accelerating translational innovations. Clin Transl Sci 8(5):542-552. https:// doi.org/10.1111/cts.12266

Wooten KC, Rose RM, Ostir GV, Calhoun WJ, Ameredes BT, Brasier AR (2014) Assessing and evaluating multidisciplinary translational teams: a mixed methods approach. Eval Health Profession 37(1):33-49. https://doi.org/ $10.1177 / 0163278713504433$
Wu L, Wang D, Evans JA (2019) Large teams develop and small teams disrupt science and technology. Nature 1. https://doi.org/10.1038/s41586-019-0941-9

Wuchty S, Jones BF, Uzzi B (2007) The increasing dominance of teams in production of knowledge. Science 316(5827):1036-1039. https://doi.org/10.1126/ science.1136099

Yin RK (2017) Case study research and applications: design and methods (6th edn.). Sage Publications

Zhang HH, Ding C, Schutte NS, Li R (2020) How team emotional intelligence connects to task performance: a network approach. Small Group Res 51 (4):492-516. https://doi.org/10.1177/1046496419889660

Zhang J, Scardamalia M, Reeve R, Messina R (2009) Designs for collective cognitive responsibility in knowledge-building communities. J Learn Sci 18(1):7-44. https://doi.org/10.1080/10508400802581676

\section{Acknowledgements}

A special thank you to Elizabeth Scodfidio for helping with data, images and more!. The research reported in this publication was supported by Colorado State University's Office of the Vice President for Research Catalyst for Innovative Partnerships Programme. The content is solely the responsibility of the authors and does not necessarily represent the official views of the Office of the Vice President for Research. Supported by NIH/NCATS Colorado CTSA Grant Number UL1 TR002535. Contents are the authors' sole responsibility and do not necessarily represent official NIH views. Funding and support were provided by grants from the National Science Foundation's Ecology of Infectious Diseases Programme (NSF EF-0723676 and NSF EF-1413925).

\section{Author contributions}

HBL conceptualised the study, developed the methodology, curated the data, analysed the data, conducted the investigation, worked as the project manager, managed the software, validated the data, created visualisations, reviewed and edited the paper; BF conceptualised the study, developed the methodology, curated the data, analysed the data, managed the software, validated the data, supervised all aspects of the research, created visualisations, reviewed and edited the paper; JC conceptualised the study, developed the methodology, acquired funding, supervised data collection, and reviewed and edited the paper; $\mathrm{KC}$ and SV wrote the paper, secured funding, reviewed and edited the paper; and ERF conceptualised the study, developed the methodology, supervised all aspects of the research, acquired funding, created the visualisations, reviewed and edited the paper; All authors reviewed the manuscript.

\section{Competing interests}

$\mathrm{HBL}, \mathrm{BF}, \mathrm{JC}$, and ERF declare no competing interests. KC and SV are members of the exemplary team

\section{Additional information}

Supplementary information The online version contains supplementary material available at https://doi.org/10.1057/s41599-021-00789-8.

Correspondence and requests for materials should be addressed to H.B.L.

Reprints and permission information is available at http://www.nature.com/reprints

Publisher's note Springer Nature remains neutral with regard to jurisdictional claims in published maps and institutional affiliations.

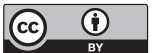

Open Access This article is licensed under a Creative Commons Attribution 4.0 International License, which permits use, sharing, adaptation, distribution and reproduction in any medium or format, as long as you give appropriate credit to the original author(s) and the source, provide a link to the Creative Commons license, and indicate if changes were made. The images or other third party material in this article are included in the article's Creative Commons license, unless indicated otherwise in a credit line to the material. If material is not included in the article's Creative Commons license and your intended use is not permitted by statutory regulation or exceeds the permitted use, you will need to obtain permission directly from the copyright holder. To view a copy of this license, visit http://creativecommons.org/ licenses/by/4.0/.

(C) The Author(s) 2021 